\title{
Dedicating "BackBone- The Spine Journal” to the Spine Research
}

\author{
Katikeya P. Pathak ${ }^{1}$
}

Orthopedic and neurosurgery community in Gujarat and across the country has been seeded with an increasing number of spine surgeons, since the past few decades. The volume of work done in the specialty has been increasing steadily, as is the confidence of the surgeons. The trend of medical specialties has been toward increased fellowship training and subspecialization. There are numerous reasons for pursuing fellowship training, including personal and financial [1]. Spine surgery is an emerging career option in the field of orthopedic surgery and neurosurgery, which is due to the increasing awareness and requirement of technical superiority of recent years, thanks to the hard work of our mentors and patrons.

In the initial days, most spine surgeries were performed at small nursing homes by enthusiasts who had sown the seeds of interest in the field of spine surgery. They helped to change the various disbeliefs among the patients regarding spine surgeries outcomes such as paralysis, bedridden status, tremendous blood loss, and exorbitant expense. Spine surgery has also been supported by the increasing number of corporate hospitals, which are well provided with the backup for the safe performance of surgery. This is not to devalue the huge volume of work being done in smaller private hospitals, which are also equipped with modern anesthetic and intensive postoperative care backup. Modern technologies of minimally invasive and endoscopic techniques, navigation system, BoneScalpel, robotic surgeries, and motion-preserving technologies have increased the utility as well as safety during spine surgeries in various setups. This is one of the possible factors behind the increasing popularity of this subspecialty $[2,3]$. The comfortable feeling, with which the spine surgeons are working, is reflected in their generally good health and fitness status; their demeanor is not haunted and worried.

In India, the number of doctors is still low, compared to the

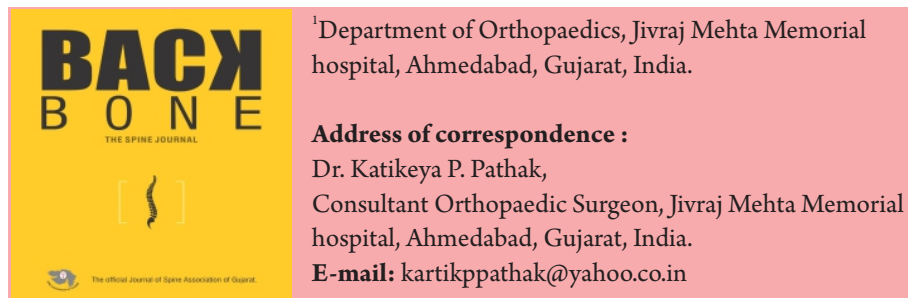

averages of the world [4], which indirectly indicates that the work is increasing tremendously. It is not important only to perform as many surgeries as possible, but it is equally imperative to spread the knowledge and information across the country and the world. The biggest orthopedic names in the country have passed away without publishing a single paper. Why did that happen? Was it merely due to the lack of journals or due to their ignorance of research and academics? Certainly not. They were as keen on teaching and passing on their skills to their juniors. They ruled our hearts but failed to make an impact in the academic world that would benefit their colleagues in the field. Therefore, it is emphasized that academic research and publishing are of lasting benefit to the subsequent generations of the state, country, and the world. Clinical work flows steadily like a perennial river, taking it to an ultimate sea of oblivion, from which it cannot be recovered for any benefit. The benefit of work and research should last long. It is, therefore, a laudable idea for the members of Spine Association of Gujarat to start a journal of their academic activities and to share their knowledge. It is indeed a "Great Leap" for the evolving spine community that will create and increase awareness in developing the field to a better level. A word of caution about the Great leap is, "Look before you leap." Any leap should always be in a concerned forward manner, not like the "Jumping frog of Calaveras County" by Mark Twain. In this, frogs sponsored for the annual race were lined up at a starting line to end up at the finish. The frogs were not tame or the trainable, and some would refuse to jump at all, and others might turn around and jump sideways or backwards. Owners were not allowed to touch or guide in any way except by hollering from the finish line. The Great Leap should not jump over priorities of work discipline such as effective communication between members, common pattern of data storage and interpolation, and accessibility. One recent study states that medical students, who conducted research leading to a publication before graduation, were more likely to be scientifically active after graduation [5]. Furthermore, the health-care professionals who conduct the research are likely to be more active in accepting newly developing technologies and in upgrading their work.

(c) 2020 | Back Bone: The Spine Journal (The Official Journal Of "Spine Association Of Gujarat") | Available on www.backbonejournal.com | doi:10.13107/bbj.2020.v01i01.002 commercial use, distribution, and reproduction in any medium, provided the original work is properly cited. 
There is an old saying about the people of Gujarat, "Gujaratio Arambhe Shoora!" meaning, Gujaratis are brave at the start, but falter to sustain or finish what they have started. I feel that this picture has changed and a match finishing spirit seems to prevail in the spine surgery community. The new journal should ignite the desire to publish research work and thereby develop interest for accepting upgradation in the field. An exponential growth in members of the Spine Association of Gujarat has occurred, indicating eagerness to learn. This journal should inculcate a system in the learning.

Electronic revolution helped the contributors to gather knowledge and in giving the best possible shape to the matter for submission. As Jacobs told that "electronic media takes on paper publishing," increasing use of various platforms such as PUBMED, MEDLINE, Scopus, and Cochrane reviews is handy on our mobile phones or computers that will enhance our speed of spreading and sharing knowledge across the world by publishing a paper in minimal time [6]. The formation of an editorial board, unbiased and experienced reviewers, wellinformed guideline for authors, convenient submission methods, faster peer-review process and publication time, and minimum publication fees would further add to the value of the journal that makes it widely acceptable. The idea is to work in a sustained organized manner, to produce a useful publication that will survive and grow better every year, serving as a genuine material to seekers. Problems need solutions, not negative criticism, which is the motto of our endeavor. A journal is very different from reading a paper, however grand the conference may be. It is a welcome step to start Spine Journal with different sections such as editorials, guest articles, current concept and other review articles, technical tips, novel case reports, innovations, complications, letter to the editor, conference proceedings, residents, and fellows research forum. I would like to urge the community to take the benefits of our initiatives with blessings from our teachers and mentors to publish our valuable contribution to the journal.

English is a gratefully borrowed language but one must not accept bad grammar, insisting that since it is not our language, we are free to twist and anyhow torture it. Editing the paper once accepted would make our research widely readable worldwide. Publication documents and records are the base for developing spine registries that form a useful base for preparation of future research work and white papers. A registry to start with may not be all encompassing but may be subject wise. This will create a cohesive feeling among the members by participation without any criticism. Evolving humbly together is the way, not to bring personal quirks or aggrandizement. Even if each worker has own records, the format and application of skills must make a paper universally acceptable. Potential authors must be painstakingly and politely approached repeatedly and convinced to apply their minds to the preparation of a presentable paper. The status of a contributor should not influence an acceptance of ineligible material. Instead, help may be given to improve it. The addition of contributors as coauthors who had worked for making it more presentable is a generous and honest measure.

Please do not hang on to some good material that you have, in the hope that you may publish it in some foreign prestigious famous journal. Publishing our work in our own journal and elevating the quality of research, automatically becomes a highly valued journal across the world. Respect our journal and our country and make others refer. In the words of The Honorable Prime Minister of India, Shri Narendra Modi, "Vocal for Local" which means, "lend your voice for what is generated in your own nation." This journal and research published should make a long-lasting effect in the minds of readers of this journal and we dedicate it to our mentors, teachers, patrons, and patients.

Be happy working together and my encouragement may always be with you.

\section{References}

1. Mead M, Atkinson T, Srivastava A, Walter N. The return on investment of orthopaedic fellowship training: A ten-year update. J Am Acad Orthop Surg 2020;28:e524-31.

2. Virk S, Qureshi S, Sandhu H. History of spinal fusion: Where we came from and where we are going. HSS J 2020;16:137-42.

3. Momin AA, Steinmetz MP. Evolution of minimally invasive lumbar spine surgery World Neurosurg 2020;140:622-6.

4. Karan A, Negandhi H, Nair R, Sharma A, Tiwari R, Zodpey S. Size, composition and distribution of human resource for health in India: New estimates using national sample survey and registry data. BMJ Open 2019;9:e025979.

5. Waaijer CJ, Ommering BW, Van Der Wurff LJ, Van Leeuwen TN, Dekker FW, NVMO Special Interest Group on Scientific Education. Scientific activity by medical students: The relationship between academic publishing during medical school and publication careers after graduation. Perspect Med Educ 2019; 8:2239 .

6. Jacobs AV. Electronic media takes on paper puablishing. Br Dent J 2000;188:1745
Conflict of Interest: NIL Source of Support: NIL

\section{How to Cite this Article}

Pathak KP | Dedicating "BackBone- The Spine Journal” to the Spine Research| Back Bone: The Spine Journal | October 2020-March 2021; 1(1):3-4. 